\title{
América do Sul e os desafios da integração regional: a UNASUL como paradigma na cobertura do Portal teleSUR
}

\author{
South America and the challenges of regional integration: UNASUR as a \\ paradigm in the coverage of the teleSUR Portal
}

\section{América del Sur y los desafíos de la integración regional: UNASUL como paradigma en la cobertura del Portal teleSUR}

\author{
Domingos Alves de Almeida \\ Li-Chang Shuen ${ }^{2}$
}

\begin{abstract}
Salgo a caminar. Por la cintura cósmica del sur. Piso en la región. Más vegetal del viento y de la luz. Siento al caminar. Toda la piel de América en mi piel. $Y$ anda en mi sangre un río. Que libera en mi voz Su caudal. (Canción con todos - Mercedes Sosa).
\end{abstract}

\begin{abstract}
Resumo
Este trabalho tem como objetivo discutir o papel da União de Nações Sul-americanas (Unasul) no processo de integração regional da América do Sul e analisar os desafios enfrentados por esse bloco geopolítico na atualidade. Utilizamos a perspectiva teórica da integração regional e do campo da comunicação e evocamos os preceitos da Teoria Construcionista (SOUSA, 2002). Além da revisão de literatura, utilizamos como metodologia a Análise do Discurso (AD) de vertente francesa, na perspectiva de Eni Orlandi (2010), aplicada à cobertura do portal de notícias da rede de televisão teleSUR, especificamente sobre a X Cúpula Unasul, realizada no dia 28 de janeiro de 2016, em Quito, capital equatoriana e sede da entidade. Aponta-se para a construção, ainda que discursiva, de uma autonomia regional, baseada nas potencialidades da América do Sul.
\end{abstract}

\begin{tabular}{|c|c|}
\hline & Acesse este artigo online \\
\hline \multirow{2}{*}{ 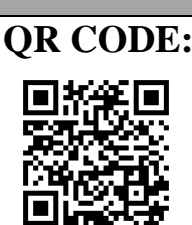 } & $\begin{array}{l}\text { Website: } \\
\text { http://www.revistas.ufg.br/index.php/ci }\end{array}$ \\
\hline & $\begin{array}{l}\text { DOI: } \\
\text { http://dx.doi.org/10.5216/ci.v20i1.47316 }\end{array}$ \\
\hline
\end{tabular}

Palavras-chave: América do Sul. Unasul. Integração Regional. Portal teleSUR.

\begin{abstract}
This paper aims to discuss the role of the Union of South American Nations (UNASUR) in the process of regional integration in South America and analyze the challenges faced by this geopolitical bloc

1 Mestrando do Programa de Pós Graduação em Integração Contemporânea da América Latina (ICAL), na Universidade Federal da Integração LatinoAmericana (UNILA). Graduado em Comunicação Social com Habilitação em Jornalismo pela Universidade Federal do Maranhão (UFMA). Bolsista do Programa de Demanda Social UNILA. Brasil, Imperatriz (MA). Brasil, Maranhão, Imperatriz. E-mail: domingos.jzufma@ gmail.com 2 Professora Adjunta do Departamento de Comunicação Social da Universidade Federal do Maranhão. Doutora em Ciências Sociais pelo Centro de Pesquisa e Pós-Graduação sobre as América da Universidade de Brasília. Brasil, São Luís (MA). Brasil, Maranhão, São Luís. E-mail: lichangshuen@gmail.com
\end{abstract}

Comun. \& Inf., Goiânia, GO, v. 20, n. 1, p. 57-72, jan./jun. 2017 
today. We use the theoretical perspective of regional integration and the field of communication evoking the precepts of the Constructionist Theory (SOUSA, 2002). In addition to the literature review, we used as a methodology the French Speech Discourse Analysis (AD), from Eni Orlandi's perspective (2010), applied to coverage of the television news portal teleSUR, specifically on the X Summit Unasul, held On January 28, 2016, in the Ecuadorian capital, Quito, the seat of the entity. It points to the construction, albeit discursive, of a regional autonomy, based on the potentialities of South America

Keywords: America. Unasur. Regional Integration. Portal teleSUR.

\section{Resumen}

Este trabajo tiene como objetivo discutir el papel de la Unión de Naciones Suramericanas (Unasur) en el proceso de integración regional en sur América con el fin de analizar los desafíos que enfrenta este bloque geopolítico actualmente. Utilizamos la perspectiva teórica de la integración regional y en el campo de la comunicación, traemos los principios de la Teoría Construccionista (SOUSA, 2002). Además de la revisión de la literatura, se utilizó como metodología, el Análisis del Discurso (AD) del lado francés, aplicado a la cobertura del Portal de Noticias de la red teleSUR, específicamente sobre la X Cumbre de Unasur celebrada el 28 de enero de 2016, en la capital ecuatoriana, sede de la organización. Apunta a la construcción discursiva, de una autonomía regional, basada en el potencial de América del Sur.

Palabras-clave: América del Sur. Unasur. Integración Regional. Portal teleSUR.

\section{INTRODUÇÃO}

o longo da história, a América do Sul passou por diversos processos de
integração, principalmente políticos e econômicos. As primeiras
experiências são datadas ainda do período colonial, com os vice-reinados do Império Espanhol e, posteriormente, com a Grã-Colômbia. Entretanto, o século XVII ficou marcado como o período de desintegração Sul-Americana, com o fim desses blocos geopolíticos, mas não das iniciativas integracionistas no subcontinente.

Durante os séculos XX e XXI, surgiram inúmeras propostas de criação de instituições supranacionais de integração regional, predominantemente, blocos geoeconômicos, em busca de promover acordos em distintas áreas. Como exemplo, podem-se destacar os acordos comercias celebrados em blocos e implementados em prol de redução gradual das tarifas alfandegárias a fim de potencializar o fluxo de mercadorias entre os países-membros e estimular a concorrência em determinados setores de suas economias.

Com vocação integracionista, a região Sul-Americana foi aos poucos criando e/ou consolidando propostas que pudessem contribuir para um efetivo processo de integração entre as nações da América do Sul. No último meio século, inúmeras instituições foram criadas nesse sentido, como o Pacto Andino, fundado em 1969 e que mais tarde viria a se tornar a Comunidade Andina de Nações (CAN). Destaca-se ainda o Tratado de Cooperação Amazônica 
(TCA), assinado em 1978, vindo a tornar-se a Organização do Tratado de Cooperação Amazônica (OTCA) em 1998.

A partir de 1985, Brasil e Argentina iniciaram negociações no sentido de construírem "um processo de integração bilateral gradual, com o objetivo central de promover o desenvolvimento econômico, ao qual se juntaram, em 1991, Paraguai e Uruguai, formando-se assim o [Mercado Comum do Sul] Mercosul” (GUIMARÃES, 2007, p. 179). E, em 2012, foi a vez da Venezuela entrar como membro efetivo do bloco.

No entanto, com todas essas propostas integracionistas, o Sul ainda carecia de iniciativas de integração para além do caráter estritamente econômico. Esse aspecto não era suficiente para abarcar o dinamismo e a complexidade de uma região tão diversa como a América do Sul e promover uma integração que envolvesse as distintas características regionais. Pensando nisso, em 2004, os líderes das nações Sul-Americanas deram início à criação da Comunidade SulAmericana de Nações, hoje denominada União de Nações Sul-americanas (Unasul).

No dia 23 de maio de 2008, em Brasília, os representantes políticos dos 12 países SulAmericanos - Argentina, Bolívia, Brasil, Chile, Colômbia, Equador, Guiana, Paraguai, Peru, Suriname, Uruguai e Venezuela - assinaram o Tratado de Brasília, formalizando a criação da entidade e seus delineamentos. A Unasul conta, também, com a participação do México e do Panamá como membros observadores.

A partir de então, a Unasul se transformou em um dos organismos supranacionais de maior relevância no continente americano, não só pela abrangência, uma vez quem engloba todos os países da região sul, mas também pelo potencial econômico, político, social, cultural e ambiental que possui. Nesse sentido, o presente trabalho tem como objetivo discutir o papel da Unasul no processo de integração regional da América do Sul e analisar os desafios enfrentados por esse bloco geopolítico na atualidade.

Para verificar os efeitos da Unasul na região, fazemos, além da revisão de literatura, uma análise discursiva da cobertura do Portal de notícias teleSUR, sobre a X Cúpula do bloco, realizada no dia 28 de janeiro de 2016, em Quito, capital equatoriana e sede da entidade. Do campo epistêmico da comunicação, utilizamos os aportes da Teoria Construcionista (SOUSA, 2002). A metodologia utilizada é a Análise do Discurso (AD) de vertente francesa, na perspectiva de Orlandi (2010).

\section{INTEGRAÇÃO SUL-AMERICANA}


A América do Sul passa por um profundo processo de mudanças na atualidade, com o retorno da ofensiva neoconservadora ao poder, que ameaça, inclusive, os significativos avanços no sentido da integração regional. Essa ofensiva ameaça suprimir, em termos, conquistas sociais alcançadas nas últimas décadas do século XX e nesses anos do século XXI, quando da chegada de governos autodenominados de esquerda ao poder, que encaminharam a América do Sul rumo à introspecção autônoma, consolidando esforços para criar mecanismos de fortalecimento das instituições locais e inserção da região no cenário global.

A trajetória recente da América do Sul revela um continente que, em plena crise do capitalismo global, se converteu em modelo de autonomia e de revigoramento das instituições democráticas, do desenvolvimento econômico e da diminuição da pobreza. Promovida por governantes eleitos no século XXI, a estratégia política de uma integração regional para além dos circuitos meramente comerciais logrou construir uma inédita aproximação entre os Estados e sociedades da região, bem como afirmar o compromisso em prol da superação solidária das dificuldades inerentes ao processo da integração. Destaque-se o desempenho da diplomacia na coordenação das políticas externas do continente voltadas para a inserção autônoma da região em um mundo ainda em busca da multipolaridade (SARTI, 2013, p. 24).

Nota-se assim, que a possibilidade de integração regional surgiu como um caminho possível, ainda que trabalhoso, para que países que seguidamente se viam como competidores passassem a cooperar entre si, em busca de uma unidade comum. Entretanto, mesmo com todos esses esforços e conquistas, alguns retrocessos ocorreram no curso da integração nos últimos anos. A retomada do poder por governos neoconservadores possibilitou que alguns países da região direcionassem suas políticas externas para os Estados Unidos, Europa e/ou Ásia. Nesse sentido, destacam-se os acordos bilaterais celebrados entre países Sul-Americanos e EUA, como a Cooperação Econômica da Ásia e do Pacífico (Apec).

Além disso, vale ressaltar que esses acordos se dedicam a privilegiar, quase que exclusivamente, aspectos econômicos, característica que difere das propostas de integração dos blocos Sul-Americanos. De acordo com Carvalho e Rosevics (2013), os Estados e as sociedades subdesenvolvidas, periféricas e ex-coloniais, como as da América do Sul, têm como objetivo supremo o desenvolvimento econômico, mas também, político e social.

Conforme destaca Sarti (2013), os povos passaram a ser entendidos pelos governantes como instrumentos estratégicos para a promoção dos aspectos integracionistas da região.

As relações de integração política e econômica pautaram-se sob a égide de um desenvolvimento que não se mede apenas pela riqueza da economia de um país ou de uma região, mas se avalia pela extensão e pela qualidade dos direitos que proporciona a seus povos. Ressalte-se ainda a relevância das políticas sociais numa nova mirada em prol dos avanços da educação, da

Comun. \& Inf., Goiânia, GO, v. 20, n. 1, p. 57-72, jan./jun. 2017 
ciência e da tecnologia em novas formas de produção do conhecimento no continente (SARTI, 2013, p. 24).

No intento de preservar e fortalecer a soberania dos Estados, afastar os riscos de possíveis intervenções externas na região e buscando incluir cada vez mais os povos no processo de integração regional, algumas iniciativas foram concebidas. Entre elas, está a criação da Aliança Bolivariana para os Povos da Nossa América (Alba) e, claro, a União das Nações Sul-Americana (Unasul), somando-se a outros organismos regionais com incidência mais ampla, como a recém-criada Comunidade de Estados Latino-americanos e Caribenhos (Celac) (SARTI, 2013).

Nesse contexto, cabe ressaltar também que a integração regional da América do Sul ainda é um processo em construção que enfrenta imensos desafios por conta das profundas assimetrias e desigualdades sociais que marcam a história desse continente. Juntam-se a esses fatores, problemas crônicos comuns à sociedade Sul-Americana, como a concentração da terra e dos meios de comunicação e a crise de representatividade dos partidos políticos, que até ameaçam as conquistas democráticas (SARTI, 2013).

Oliveira (2013) chama atenção para os desafios que existem ao tentar promover a integração, unindo os aspectos econômicos e sociais. Para o autor, lograr o êxito de colocar blocos regionais, formados por países da periferia, no cenário internacional, é um processo árduo e que demanda muito esforço, mas que está sendo levado adiante pelos países SulAmericanos, evidenciando o desenvolvimento de uma forte tendência para um regionalismo subcontinental.

Um dos desafios mais importantes do processo de integração regional é a promoção da coesão econômica e social no espaço comum construído ao longo dos anos. Neste sentido, o significado das políticas públicas e dos instrumentos estatais com vista ao desenvolvimento regional torna-se consistente em face dos desafios impostos pela mundialização, em especial nas experiências de integração regional nos países periféricos (OLIVEIRA, 2013, p. 49).

É interessante destacar que os países da América do Sul, já desde o século XIX, vêm compartilhando, ainda que em nível de discurso, anseios por uma unidade subcontinental. Esses anseios visam atender as demandas da região, no que diz respeito à infraestruturas adequadas que possibilitem um fluxo maior de mercadorias, pois há carência de portos, estradas, hidrovias, ferrovias e ductos para transporte de combustíveis, o que coloca uma verdadeira barreira física aos fluxos entre os países do subcontinente. 
A constituição de investimento em infraestrutura que possibilite a articulação e a integração física do subcontinente sul-americano é, sem dúvida, uma temática marcante neste início do século XXI. O surgimento do projeto da Iniciativa para a Integração da Infraestrutura Regional Sul-Americana (IIRSA), no ano 2000, representou um importante marco no processo de integração da América do Sul. A infraestrutura do Plano IIRSA visa construir na América do Sul, através da liberalização do comércio recíproco dos bens e serviços, uma infraestrutura energética, de telecomunicações e uma malha viária e portuária comuns (OLIVEIRA, 2013, p. 49).

A partir desses pressupostos, entende-se que a integração física surge como elemento primordial para o desenvolvimento da unidade política, econômica e social sul-americana. Entretanto, alcançar êxito com essa proposta de integração requer a adoção de medidas efetivas e substanciais para enfrentar e superar "as assimetrias de desenvolvimento dos países da região" (OLIVEIRA, 2013, p. 56). E, no intento de sanar essas assimetrias é que se idealiza a Iniciativa para a Integração da Infraestrutura Regional Sul-Americana (IIRSA), no âmbito da Unasul (OLIVEIRA, 2013).

\section{UNASUL: ALTERNATIVA À INTEGRAÇÃO DA AMÉRICA DO SUL?}

A União de Nações Sul-Americanas passou a ser formalmente idealizada na III Cúpula de Presidentes da América do Sul, datada de 8 de dezembro de 2004, quando os representantes dos doze países da região assinaram a Declaração de Cuzco, um documento preliminar que anunciava a fundação e as intenções da então denominada Comunidade Sul-Americana de Nações.

Os diálogos seguiram até o dia 23 de maio de 2008, quando foi assinado o Tratado Constitutivo da Unasul, por ocasião da Terceira Cúpula de Chefes de Estado, realizada em Brasília. Esse Tratado definiu as instalações da sede da entidade, em Quito, Equador, do Parlamento Sul-Americano em Cochabamba, na Bolívia, e a sede do Banco do Sul, em Caracas, na Venezuela. Para Guimarães (2007), essa organização "se pretenderia semelhante à União Africana, na África; à União Europeia na Europa; à ASEAN, na Ásia; e ao MCCA, na América Central” (GUIMARÃES, 2007, p. 181). Ainda segundo o autor, as negociações que levaram à concretização da Unasul encontraram diversas resistências, entre elas:

Primeiro, a de países que celebraram acordos de livre comércio com os EUA; segundo, a de países que dão prioridade ao fortalecimento do Mercosul e que acreditam que o Brasil estaria 'trocando' o Mercosul pela UNASUL; terceiro, a de países que consideram ser necessária uma organização mais audaciosa, com base na solidariedade e na cooperação e não naquilo que consideram ser o individualismo 'mercantilista' das preferências comerciais, dos projetos de investimento e do livre comércio (GUIMARÃES, 2007, p. 181).

Comun. \& Inf., Goiânia, GO, v. 20, n. 1, p. 57-72, jan./jun. 2017 
Diante dessa diversidade política, social, cultural e geográfica e, considerando o fim da polaridade mundial, marcado pela Guerra Fria, em que a América do Sul esteve à sombra dos Estado Unidos, tornando os países do subcontinente os menos conflagrados do mundo, fez-se perceber que havia a necessidade de aproximação entre os vizinhos sulistas. Desde então, as iniciativas para a integração se multiplicaram, entre elas, o Mercosul, de 1991, e, em 2008, a mais representativa delas na atualidade, a União de Nações Sul Americanas (Unasul).

Formada pelos 12 países do subcontinente, esse bloco geopolítico se configura como o único, exclusivamente da América do Sul, a congregar todas as nações da região. Sendo, portanto, um dos mais importantes do mundo, tanto em volume populacional, territorial, social como de bens primários. Assim, essas alianças em bloco impedem que os países sejam “absorvidos como simples periferias de outros grandes blocos, sem direito à participação efetiva na condução dos destinos econômicos e políticos desses blocos, os quais são definidos pelos países que se encontram em seu centro" (GUIMARÃES, 2007, p. 171).

O Tratado de Brasília, doravante Tratado Constitutivo da União de Nações SulAmericanas (Unasul), traz uma proposta diferenciada de integração regional desde o seu preâmbulo. O texto afirma que as nações da América do Sul estão:

Apoiadas na história compartilhada e solidária de nossas nações, multiétnicas, plurilíngues e multiculturais, que lutaram pela emancipação e unidade SulAmericanas, honrando o pensamento daqueles que forjaram nossa independência e liberdade em favor dessa união e da construção de um futuro comum (UNASUL, 2008, p. 02).

Nota-se que a entidade evoca as peculiaridades e a história da região para elucidar a partir de quais pressupostos surgem sua proposta integracionista da América do Sul. É uma demonstração visível de nova tendência de uma integração mais abrangente e social. "Trata-se de uma concepção mais propositiva da integração a qual aponta para a criação de um novo espaço regional, visando o desenvolvimento e não somente a adoção de medidas de liberação do comércio" (OLIVEIRA, 2013, p. 56).

$\mathrm{O}$ artigo $1^{\mathrm{o}}$ do tratado de Brasília define a Unasul como "uma organização dotada de personalidade jurídica internacional”. A organização propõe uma integração para além da América do Sul, ao se dispor em contribuir, também, para o fortalecimento da unidade latinoamericana e caribenha. E faz essa proposição:

Afirmando sua determinação de construir uma identidade e cidadania sulamericanas e desenvolver um espaço regional integrado no âmbito político, econômico, social, cultural, ambiental, energético e de infra-estrutura, para

Comun. \& Inf., Goiânia, GO, v. 20, n. 1, p. 57-72, jan./jun. 2017 
contribuir para o fortalecimento da unidade da América Latina e Caribe (UNASUL, 2008, p. 01).

Aqui, destaca-se a forma abrangente a que se dispõe a atuar, construindo um espaço integrado em diversos âmbitos. Esse processo integracionista é entendido como um instrumento indispensável para levar ao desenvolvimento e em direção a um maior dinamismo comercial e à superação dos obstáculos estruturais para o desenvolvimento social (OLIVEIRA, 2013).

No que concerne à estrutura orgânica da instituição, o artigo $4^{\circ}$ determina que essa é definida em quatro instâncias: 1- O Conselho de Chefas e Chefes de Estado e de Governo; 2 O Conselho de Ministras e Ministros das Relações Exteriores; 3 - O Conselho de Delegadas e Delegados; e 4 - A Secretaria Geral. Já o capítulo 6 discorre sobre as atribuições de cada um dos órgãos que compõem a estrutura decisória da Unasul. Os rumos da entidade são no sentido de seguir os avanços já alcançados em torno do processo regional. Tanto a Unasul como a sua proposta integracionista da América do Sul foram fundadas sob os seguintes princípios basilares:

Irrestrito respeito à soberania, integridade e inviolabilidade territorial dos Estados; autodeterminação dos povos; solidariedade; cooperação; paz; democracia, participação cidadã e pluralismo; direitos humanos universais, indivisíveis e interdependentes; redução das assimetrias e harmonia com a natureza para um desenvolvimento sustentável (UNASUL, 2008, p. 01).

Esses princípios de autonomia dos povos, busca pela preservação da natureza e pelo fim, ou pelo menos redução, das assimetrias sociais dos países membros, são as bases de sustentação que norteiam a atuação da União de Nações Sul-Americanas, conforme é assegurado através do objetivo principal do bloco:

Construir, de maneira participativa e consensuada, um espaço de integração e união no âmbito cultural, social, econômico e político entre seus povos, priorizando o diálogo político, as políticas sociais, a educação, a energia, a infra-estrutura, o financiamento e o meio ambiente, entre outros, com vistas a eliminar a desigualdade socioeconômica, alcançar a inclusão social e a participação cidadã, fortalecer a democracia e reduzir as assimetrias no marco do fortalecimento da soberania e independência dos Estados (UNASUL, 2008, p. 02).

Do exposto, destaque para o compromisso assumido pelas nações signatárias da Unasul em construir uma integração participativa, valorizando os aspectos culturais, sociais e políticos dos povos. Ademais disso, asseguram dar prioridade às políticas sociais, educativas e ambientais, comprometendo-se, sobretudo, a eliminar as desigualdades socioeconômicas e promover a inclusão social.

Comun. \& Inf., Goiânia, GO, v. 20, n. 1, p. 57-72, jan./jun. 2017 
Para complementar essa iniciativa de integração protagonizada pela Unasul no intervalo de tempo entre as discussões sobre os delineamentos do bloco e os anos posteriores à sua fundação, a América do Sul experimentou a criação de instituições paradigmáticas de fomento ao projeto integracionista como, por exemplo, a rede de comunicação teleSUR. Guimarães explica a importância de instituições voltadas ao universo midiático, atuando desde e para a América do Sul:

É essencial a integração das comunicações aéreas, pela sua importância para a economia e a política, assim como da mídia, em especial a televisão, essencial à formação do imaginário sul-americano, através do conhecimento da vida política, econômica e social dos países da região, hoje desconhecida do grande público e, portanto, fonte de toda sorte de preconceitos e manipulações que envenenam a opinião pública e afetam os discursos, as atividades e as decisões políticas. A TV Brasil - Canal Integración e a TELESUR são experiências não hegemônicas de integração de comunicações (GUIMARÃES, 2007, p. 182-183).

Nesse ponto, é interessante ressaltar que na América do Sul há uma constante disputa pelo domínio do seu espaço simbólico, em que a região é colocada em condição subalterna em relação aos grandes centros. Nessa disputa estão grandes veículos de comunicação estrangeiros (CNN, BBC, Univisión), formando verdadeiros impérios midiáticos, que retratam a região de forma parcial ou desfavorável sob vários aspectos. Por isso, os países Sul-Americanos iniciaram um processo significativo de contra hegemonia.

\section{ANÁLISE DA COBERTURA DO PORTAL TELESUR}

O Portal de notícias teleSUR é mantido pela rede de comunicação multiestatal Televisión del Sur, fundada pelo ex-presidente venezuelano, Hugo Chávez, e levada ao ar no dia 24 de julho de 2005. A rede, inicialmente, contou com a contribuição de Argentina (20\%), Cuba (19\%) e Uruguai (10\%). Recentemente, o presidente Argentino, Maurício Macri, retirou o país da sociedade da teleSUR, por conta de seu alinhamento políticos voltado à direita. Segundo Nogueira (2012, p. 88), desde o início, a teleSUR deixou claro seu comprometimento com os ideais e interesses bolivarianos, explicitando sua missão a "serviço da integração das nações e povos da América Latina e Caribe", defendendo a informação "veraz e oportuna" como um direito dos povos.

O universo dessa pesquisa é a cobertura jornalística realizada pelo Portal teleSUR (http://www.telesurtv.net/). O recorte são as matérias que foram veiculadas no dia 28 de janeiro de 2016, abordando a X Cúpula da União de Nações Sul-Americanas (Unasul), realizada em Quito. Assim, o corpus levantado para o estudo consta de cinco matérias do gênero notícia: 1 Comun. \& Inf., Goiânia, GO, v. 20, n. 1, p. 57-72, jan./jun. 2017 
Cancilleres de Unasur revisan agenda común en Quito; 2 - Consejo de cancilleres de Unasur aborda coyuntura económica; 3 - Venezuela asumirá presidencia pro tempore de UNASUR en abril; 4 - Rousseff y Correa coinciden en fortalecer la integración; 5 - Inició la reunión de cancilleres de la Unasur en Quito.

Para iniciar esta análise, faz-se necessário entender que a notícia é um produto "fabricado", a partir da convergência de um conjunto de forças - ação pessoal, ação social e ação cultural - que determinam o que e como algo será noticiado. Fatores históricos e os meios físicos e tecnológicos (como e onde será veiculada a notícia) também incidem sobre a produção. E isso explica o porquê das notícias que temos e por que elas são como são (SOUSA, 2002).

A partir do exposto, inicia-se a análise destacando que a cobertura do portal volta-se inteiramente para defender as iniciativas de integração que envolvem a América do Sul como, por exemplo, a União de Nações Sul-Americanas (Unasul) e a Comunidade de Estados LatinoAmericanos e Caribenho (Celac). Essa correlação de blocos é feita porque a IV Cúpula da Celac aconteceu um dia antes da X Cúpula da Unasul. E, conforme destaca a emissora, ambos os encontros acontecem na sede do bloco Sul-Americano, em Quito.

Integración - Tras finalizar la cumbre de jefes de Estados de la Comunidad de Estados Latinoamericanos y Caribeños (CELAC), los países integrantes de este bloque acordaron implementar una lucha conjunta contra el virus zika, respalda los diálogos de paz colombianos y exigir a Estados Unidos (EE.UU.) el levantamiento del bloque económico, financiero y comercial contra Cuba. De igual forma, fueron aprobadas un total de 20 declaraciones especial en defensa de los intereses de los pueblos de América Latina y el Caribe. Algunas de las resoluciones acordadas por los países de la CELAC están relacionadas con la defensa de la soberanía, la seguridad alimenticia, las políticas antidrogas, la lucha contra la corrupción y el desarrollo energético. Por su parte, el presidente de Ecuador, Rafael Correa, destacó la necesidad de que la CELAC reemplace a la OEA como plataforma para abordar las problemáticas de la región, y defender los intereses de sus países miembros (PORTAL teleSUR, 28 DE MARÇO DE 2016).

A teleSUR faz questão de ressaltar que, dos 33 países que compõem a Celac, 12 deles são Sul-Americanos e signatários da Unasul. Além de ser uma forma de realçar a importância do bloco sulista, aponta para um desejo latente por uma aproximação mais consistente entre os dois blocos que, inclusive, é fomentado por mandatários, como a então presidenta Dilma Rousseff (Brasil) e Rafael Correa (Equador) e pelo Secretário Geral da entidade, Ernesto Samper.

Outros apontamentos dizem respeito aos encaminhamentos feitos durante a Cúpula da Unasul, entre eles a discussão sobre a possibilidade de se criar a cidadania Sul-Americana para 
beneficiar os cidadãos da América do Sul. O Portal evoca as falas do secretário geral da Unasul, Ernesto Samper, para assegurar a assertiva de que a cidadania na região tem como foco "facilitar la movilidad a todos los suramericanos para que puedan trabajar en cualquier parte de la región y para que puedan estudiar".

Ainda segundo a cobertura, os chanceleres discutiram diversos temas de interesse comum. O que nos faz entender que os países participantes da Cúpula mantêm fortes delineamentos para solucionar seus problemas, principalmente econômicos, em conjunto. Notase, também, que há certo destaque para atuação da Venezuela junto ao órgão supranacional.

Pode-se atribuir dois motivos para esse fato: primeiro, ao alinhamento políticoideológico da rede teleSUR com o governo de Caracas e, segundo, a presidência do Conselho de Chanceleres da entidade passou do uruguaio Rodolfo Nin Novoa para a venezuelana Delcy Rodríguez, a quem foi destinado amplo espaço para expor suas perspectivas de gestão à frente do bloco. Entre as falas destacadas está uma em que ela assegura que a reunião da Cúpula aconteceu em um espírito de coincidência, onde prevaleceu a fraternidade.

Outro destaque foi dado à fala de Rodriguéz, em que afirma que os países acordaram em fortalecer o investimento e o comércio intrarregional, para prevalecer, guardar e proteger os avanços sociais dos países. Ademais, a cobertura da teleSUR informa que a Venezuela assume a presidência da Unasul com o objetivo de trabalhar de maneira conjunta para fortalecer a economia da região diante da crise mundial e a baixa dos preços do petróleo. E reforça que, embora haja prioridade para o tema econômico, as políticas sociais não serão deixadas de lado.

La canciller de Venezuela, Delcy Rodríguez, aseguró este jueves que el Consejo de Ministros de Relaciones Exteriores de la Unión de Naciones Suramericanas (Unasur), que se celebra en Quito, capital de Ecuador, abordó temas importantes para la región, entre ellos la coyuntura económica mundial. En una entrevista para teleSUR, Rodríguez indicó que la reunión de cancilleres de la Unasur se dio "en un espíritu de coincidencia" y "prevaleció la fraternidad". La canciller venezolano indicó que acordaron "fortalecer la inversión y el comercio intraregional, para prevalecer, guardar y proteger los avances sociales de nuestros países". Indicó que Venezuela está lista para recibir la presidencia pro tempore de la Unasur, que está actualmente está en manos de Uruguay, cuyo canciller Rodolfo Nin Novoa presentó el balance de su gestión. Rodríguez aseguró que Venezuela asumirá la presidencia por tempore de la Unasur en abril, con el reto de trabajar de manera conjunta para fortalecer la economía de la región ante la crisis mundial y la baja de los precios del petróleo. Aseveró que la prioridad del tema económico se mantendrá, sin dejar de lado las políticas sociales. "Estamos ya prestos y listos para recibir la Presidencia pro témpore seguir trabajando, como hermanos que somos, con el ambiente que se dio en esta reunión de fraternidad y de coincidencia", expresó (PORTAL teleSUR, 28 DE MARÇO DE 2016). 
Explicitamente, a emissora busca construir um clima de harmonia entre os países da Unasul, a partir da perspectiva da Venezuela, que assume a presidência do órgão enfrentando forte resistência de países como a Argentina. A cobertura jornalística ainda realça a disposição da ministra venezuelana que se compromete em trabalhar para dar projeção cultural aos países de União de Nações Sul-Americanas.

Outro personagem que ganha destaque significativo nessa cobertura analisada é o secretário geral de Unasul, Ernesto Samper. A teleSUR ressalta que ele convocou os chefes de Estados a estarem atentos à crise econômica e dispostos a buscarem alternativas em bloco para enfrentar a situação. Samper, que é chamado pela emissora de o máximo representante do organismo regional, pediu que as nações fizessem melhor uso dos recursos naturais da região e redistribuíssem equitativamente a produção para fortalecer as economias de seus países.

O secretário dá grande ênfase ao fato de os países da América do Sul terem retirados 120 milhões de pessoas da situação de pobreza extrema nas últimas décadas, pontuando que seria injusto que essas pessoas voltassem a viver nessas condições de vida. Ao que parece, toda essa notoriedade dada a Ernesto Samper pode ter uma justificativa. Ele, durante sua fala na Cúpula, reconheceu os esforços da Venezuela, Cuba, Chile e Uruguai no processo de paz na Colômbia. Aqui, cabe enfatizar que Venezuela e Colômbia já protagonizaram situações de conflitos entre si, que exigiram sérios esforços da diplomacia regional.

O processo de paz na Colômbia repercutiu também através de falas da chanceler colombiana, Maria Ángela Holguín, que se referiu às negociações entre o governo de seu país e as Forças Armadas Revolucionárias da Colômbia (Farc), que estão acontecendo em Havana, capital de Cuba. Holguín solicitou apoio da Unasul para avançar e consolidar o fim do conflito armado.

Assunto que igualmente ganhou repercussão foi a defesa dos chefes de Estado para que Celac e Unasur se unam no enfrentamento à conjuntura econômica global. Rafael Correa e Dilma Rousseff ressaltaram a importância de fortalecer a integração regional a partir do impulso da economia Latino-Americana para encarar o cenário internacional. A mandatária brasileira advertiu que esses problemas regionais, agravados pela queda dos preços do petróleo e a desaceleração da economia no mundo, são fatores que mostram a necessidade uma maior unidade da América Latina.

O presidente do Equador, Rafael Correa, evidenciou o papel de liderança desempenhado pelo Brasil nos processos de integração regional, em um contexto econômico difícil para os países da América Latina. Atribui-se essa liderança porque o país é o principal provedor de

Comun. \& Inf., Goiânia, GO, v. 20, n. 1, p. 57-72, jan./jun. 2017 
financiamento regional. As matérias da teleSUR frisaram que Rousseff e Correa se propuseram a concretizar projetos em comum, como o eixo Manta-Manaus, que permitiria unir as costas do Pacífico e do Atlântico, possibilitando que os produtos brasileiros cheguem a costa do Pacífico sem passar pelo Canal do Panamá, e avançar para os mercados asiáticos.

Los jefes de Estado destacan que necesaria la unión de la Celac y Unasur para afrontar la coyuntura económica global. Los mandatarios de Ecuador, Rafael Correa, y de Brasil, Dilma Rousseff, resaltaron este martes la importancia de fortalecer la integración regional a partir del impulso de la economía latinoamericana para afrontar el escenario internacional. Rousseff y Correa se reunieron en Quito (capital) para revisar asuntos de interés bilateral y aprovecharon para tratar temas como la incidencia del complejo marco económico internacional en la región. La mandataria brasileña advirtió que esta "incidencia preocupante" a causa de la caída de los precios del petróleo y la desaceleración de la economía en el mundo son factores que "hacen necesaria una mayor unidad de América Latina". [...] el jefe de Estado ecuatoriano, enfatizó en el fortalecimiento de la integración regional mediante la consolidación de los objetivos de la Comunidad de Estados Latinoamericanos y Caribeños (Celac) y la Unión de Naciones Suramericanas (Unasur). [...] El encuentro entre los líderes de Estado se produjo la víspera de la IV Cumbre de la Celac que se celebrará este miércoles con representantes de 33 países del bloque. Los gobernantes indicaron que concretarán proyectos en común como el eje Manta-Manaos, el cual permitiría unir las costas del Pacífico y el Atlántico. [...] En ese sentido, Rousseff y Correa se comprometieron a consolidar su relación comercial para hacer llegar exportaciones no petroleras, en particular el banano, el camarón y el atún. Correa además resaltó la necesidad de fortalecer su tejido industrial como autobuses y camiones a través de la comercialización de productos ensamblados en Brasil, proveedor de financiación regional (PORTAL teleSUR, 28 DE MARÇO DE 2016).

Percebemos que há uma articulação consistente dentro da União de Nações SulAmericanas (Unasul), no sentido de promover uma autossuficiência em termos de infraestrutura e, consequentemente, em termos econômicos, capaz de atender às demandas regionais. Especificamente sobre o eixo Manta-Manaus, a região Sul-Americana busca consolidar sua autonomia e aprimorar suas relações econômicas com a Ásia, um dos principais parceiros comerciais da América do Sul, livrando-se da dependência do Canal do Panamá. Há que se considerar ainda que os EUA possuem forte influência sobre o Canal, e esse movimento autonomista da Unasul afeta diretamente os interesses norte-americanos.

\section{CONSIDERAÇÕES FINAIS}

Com apenas oito anos de existência, a União de Nações Sul-Americanas (Unasul) apresenta certa maturidade na condução das iniciativas integracionistas da região. Pelo menos é o que explicita a cobertura do Portal teleSUR sobre a X Cúpula da entidade. A explicação 
para isso pode estar no fato de que esse bloco, o maior da América do Sul na atualidade, esteja congregando e dando continuidade às iniciativas de integração lançadas anteriormente por outros blocos que já existiam na região, como a Organização do Tratado de Cooperação Amazônico (OTCA), o Mercado Comum do Sul (Mercosul) e Comunidade Andina de Nações (CAN).

Por ter surgido de uma iniciativa brasileira, levada adiante pelo ex-presidente Lula, há muitas críticas à Unasul, principalmente pela desconfiança de que o Brasil, juntamente com outras nações Sul-Americanas, queira substituir blocos como o Mercosul e a CAN por essa entidade mais abrangente e mais propositiva. Além das críticas, a entidade já teve que lidar com situações delicadas na região, como o golpe parlamentar no Paraguai em 2012, em que teve que aplicar a Clausura Democrática e suspender o país do bloco.

Mais recentemente, foi alvo de duras críticas do então ministro das Relações Exteriores do Brasil, José Serra, por conta de seu posicionamento contra o processo que levou à destituição da presidenta reeleita democraticamente em 2014, Dilma Rousseff. O Bloco ainda tem que discutir soluções para os problemas econômicos e sociais enfrentados pelos venezuelanos e mediar seus conflitos internos, resultados de diferenças ideológicas existentes entre alguns países e a política bolivariana de Nicolás Maduro. Essa mediação se torna ainda mais delicada porque tanto a Presidência do Conselho de Ministras e Ministros da Relações Exteriores, como a Presidência Pró-tempore da Unasul estão sob a tutela venezuelana.

É nítida a busca da Unasul pela autonomia do bloco Sul-Americano em relação ao norte do continente. Entretanto, com tantas assimetrias na região, o desafio se torna homérico, mas aos poucos esses empecilhos estão sendo transpostos. E mesmo com todos os esforços para não se constituir apenas como um bloco econômico e comercial, a entidade não consegue fugir da obviedade e da priorização dessas áreas.

Isso não significa que as áreas que estão ligadas mais diretamente com os povos, como política, social, ambiental, educativa e cultural, não tenham uma atenção relativamente diferenciada quando se compara aos demais blocos, o que já se pode considerar um grande avanço. Os próximos anos serão decisivos para sabermos se a Unasul vai progredir, estagnar ou regredir.

O processo que culminou com o controverso impedimento contra a presidenta eleita do Brasil, Dilma Rousseff, tem implicações decisivas para o futuro da instituição, considerando que o substituto da mandatária, um expoente da direita latino-americana, está realinhando a 
política externa brasileira para os Estados Unidos e Europa, colocando em cheque todo o processo integracionista regional.

Ao longo de toda a cobertura do Portal teleSUR sobre a X Cúpula da Unasul, a construção discursiva é no sentido de apresentar a entidade supranacional como o órgão a possibilitar o desenvolvimento conjunto dos países sulistas em distintos aspectos, se sobrepondo, inclusive, à Celac, organismo mais abrangente que conta com a participação dos 33 países da América Latina.

\section{REFERÊNCIAS}

CARVALHO, G. C., ROSEVICS, L. A política externa do governo Lula para a América do Sul: Unasul e Unila. In: SARTI, I. et. al. (Org.). Por uma integração ampliada da América do Sul no Século XXI. Rio de Janeiro: PerSe, 2013. p. 225-240.

GUIMARÃES, S. P. O mundo multipolar e a integração sulamericana. Comunicação \& Política, v. 25, n. 3, p. 169-189, 2007.

NOGUEIRA, S. G. "Voz a los que no la tienen": a integração regional no olhar bolivariano da Telesur. In: OLIVEIRA, RP.; NOGUEIRA, SG.; MELO, FR. (Org.). América Andina: integração regional, segurança e outros olhares [online]. Campina Grande: EDUEPB, 2012.

OLIVEIRA, A. E. As (des) articulações sub-nacionais e o processo de integração regional na América do Sul, a partir da experiência do Mercosul/Unasul. In: SARTI, I. et. al. (Org.). Por uma integração ampliada da América do Sul no Século XXI. Rio de Janeiro: PerSe, 2013. p. $49-58$

ORLANDI, E. Análise de Discurso: Princípios \& Procedimentos. São Paulo: Pontes Editores, 2010.

SARTI, I. Desafios da integração ampliada da América do Sul. In: SARTI. I. et. al (Org.). Por uma integração ampliada da América do Sul no século XXI. Rio de Janeiro: PerSe, 2013. p. $24-28$

SOUSA, J. P. Por que as notícias são como são? Construindo uma teoria da notícia. Biblioteca On-Line de Ciências da Comunicação da Universidade do Porto, Porto, 2002. Disponível em: <http://www.bocc.ubi.pt/pag/sousa-jorge-pedro-construindo-teoria-danoticia.pdf $>$. Acesso em: 22 jan. 2015.

TELESUR. Cancilleres de Unasur revisan agenda común en Quito. Portal teleSUR. 2016. Disponível em: <http://www.telesurtv.net/news/Cancilleres-de-Unasur-revisan-agendacomun-en-Quito-20160128-0018.html>. Acesso em: 05 jun 2016.

TELESUR. Consejo de cancilleres de Unasur aborda coyuntura econômica. Portal teleSUR. 2016. Disponível em: <http://www.telesurtv.net/news/Consejo-de-cancilleres-de-Unasuraborda-coyuntura-economica-20160128-0051.html>. Acesso em: 05 jun 2016. 
TELESUR. Inició la reunión de cancilleres de la Unasur en Quito. Portal teleSUR, 2016. Disponível em: <http://www.telesurtv.net/news/Inicio-la-reunion-de-cancilleres-de-laUnasur-en-Quito-20160128-0041.html>. Acesso em: 05 jun 2016.

TELESUR. Rousseff y Correa coinciden en fortalecer la integración. Portal teleSUR, 2016. Disponível em: <http://www.telesurtv.net/news/Rousseff-y-Correa-coinciden-en-fortalecer-laintegracion-20160127-0002.html>. Acesso em: 05 jun 2016.

TELESUR. Venezuela asumirá presidencia pro tempore de UNASUR en abril. Portal teleSUR, 2016. Disponível em: <http://www.telesurtv.net/news/Venezuela-asumirapresidencia-pro-tempore-de-UNASUR-20160128-0042.html>. Acesso em: 05 jun. 2016.

UNASUL. Tratado Constitutivo da União de Nações Sul-Americanas. Brasília: UNASUL, p 01-15, 2008 Disponível em: http://www.itamaraty.gov.br/images/ed_integracao/docs_ UNASUL/TRAT_CONST_PORT.pdf. Acessado em: 03 de jun 2016. 